\title{
Perioperative fluid overload increases anastomosis thrombosis in the free TRAM flap used for breast reconstruction
}

\author{
Darren Ivar Booi
}

Received: 8 March 2009/Accepted: 3 June 2010 / Published online: 22 June 2010

(C) The Author(s) 2010. This article is published with open access at Springerlink.com

\begin{abstract}
To increase perfusion pressure with vasoactive drugs may be in conflict with the opinion of the reconstructive surgeon who maintains that the systemic administration of vasoactive agents causes vasoconstriction of the pedicle artery and the microvasculature. In free flap surgery, deliberate fluid therapy is used with a minimum of vasoactive drugs. This retrospective study was performed to analyse the perioperative fluid therapy, its effect on hemodynamic parameters and on the outcome of free flap surgery. One hundred and four patients were included in this retrospective study. The muscle sparing free transverse rectus abdominis myocutaneous flap was used for breast reconstruction. Perioperative hemodynamic data was used for this study. Twenty-seven patients had one or two complications requiring return to the operating room (OR). Two cases returned to the OR because of postoperative bleeding; in 11 patients, the anastomosis was revised. The reason for surgery in the latter group was venous stasis, due to thrombus formation at the venous anastomosis. The volume of fluid therapy was significantly higher in patients who returned to the OR due to thrombus formation at the anastomosis. Based on the results of this study, restricted intravenous fluid therapy or guided fluid therapy is recommended. Invasive monitoring such as central venous pressure and invasive arterial monitoring is recommended.
\end{abstract}

Financial support NUTRIM School for Nutrition, Toxicology and Metabolism of the Faculty of Health, Medicine and Life Sciences of Maastricht University in cooperation with the University Hospital Maastricht have provided financial support for this study.

D. I. Booi $(\square)$

Department of Plastic, Reconstructive and Hand Surgery,

Maastricht University Medical Centre,

P.O. Box 5800, 6202 AZ Maastricht, The Netherlands

e-mail: darrenbooi@gmail.com
Fluid loss should be replaced, and fluid overload should be avoided when the breast is reconstructed using free-tissue transfers.

Keywords Breast reconstruction · Free flap .

Anaesthesiology

\section{Introduction}

Free-tissue transfer has become the standard treatment for autologous breast reconstruction. In breast reconstruction, postoperative complications and the final aesthetic outcomes place a significant emotional burden on the patient. Anatomical and clinical studies have increased the physiological knowledge of flaps used in breast reconstruction. However, although overall free flap success rates are above $95 \%$, thrombosis of the arterial or venous anastomosis is still a dramatic complication, which may lead to flap loss.

In contrast to the increased knowledge on flap design, little is known about the anaesthetic and perioperative management, which may have an effect on the outcome of microvascular surgery. In 1985, Macdonald proposed that it is important to maintain adequate arterial pressure and cardiac output. It is generally accepted that good perfusion pressure is essential to flap survival [1,2].

In addition to general anaesthesia, intravenous fluid is administered during surgery. Anaesthesiologists attempt to restore vascular volume based not only on clinical signs such as heart rate, arterial blood pressure and urine output but also on calculations of maintenance, third-space losses and blood loss. It is common practice to use generous amounts of fluid resuscitation since it is believed that modest hypervolaemia reduces the sympathetic tone and therefore dilates the supplying vessels to the flap. In addition, a mild 
increase in central venous pressure will increase the cardiac output.

On the other hand, restricted fluid administration has shown to improve outcome after major surgery [3]. The excessive use of fluid therapy may therefore increase the complication rate in reconstructive surgery. The reason for this retrospective study was to analyse perioperative fluid therapy, its effect on hemodynamic parameters and its effect on the outcome of the free-tissue transfer.

\section{Patients and methods}

One hundred and eight patients were included in this retrospective study. All surgical interventions were performed by experienced plastic surgeons. During the period of this study, the muscle sparing free transverse rectus abdominis myocutaneous (TRAM) flap technique was used for the reconstruction. In this surgical procedure, a small medial part of the rectus abdominis is harvested along with several lateral and medial perforating vessels of the deep inferior epigastric artery. After complete dissection, the flap is divided into four perfusion zones as previously reported [4]. All four zones were included in the flap, and the endto-end anastomosis was performed using the internal mammary artery.

All patients eligible for breast reconstruction with the muscle sparing free TRAM flap were included in the study regardless of relative risk factors such as smoking, obesity, chest wall irradiations and chemotherapy. Flap characteristics, e.g. flap weight, reconstructed breast weight, ischemia time and incidence of postoperative complications, were noted. Outpatient recording charts were used to detect any late complications such as wound dehiscence, minor partial flap loss or fat necrosis.

Using the anaesthesia operative/recovery charts, type (crystalloid or colloid) and volume of fluid therapy and hemodynamics parameters were meticulously recorded. These parameters were recorded at a 15-min interval during surgery followed by hourly recording up to discharge from the recovery area $24 \mathrm{~h}$ after surgery. Patient and flap temperature were recorded using the same time interval. The use of vasoactive medication was also recorded during this period. After completion of the anastomosis, all patients received intravenous Dextran $\left(30 \mathrm{~cm}^{3} / \mathrm{h}\right)$; this is commonly used by microsurgeons to decrease vascular thrombosis.

All data were presented as mean values \pm SEM. SPSS was used for statistical analysis. Repeated measures analysis of variance was used for analysis of all repeated measurements. Student's $t$ test was used for analysing quantitative parameters. Chi-square test was used for categorical data. A $P$ value $<0.05$ (two-tailed) was considered statistically significant.

\section{Results}

In the 108 consecutive patients, the free TRAM flap was used for secondary unilateral breast reconstruction. The anaesthesia/recovery chart was lost in two cases and was incomplete in two cases. These four cases were excluded from further analysis. For the remaining 104 patients, the perioperative data was thoroughly recorded and found suitable for inclusion in the study.

Mean age at time of operation was $48.4 \pm 0.8$ (range, $27-$ 68) years. Body mass index (BMI) was $26.3 \pm 0.5$ (range, 17.5-32.4) kg. Fifty percent of patients received radiotherapy, and $67 \%$ of the patients received chemotherapy preoperatively. Thirty-seven percent of patients received both chemo- and radiotherapy. Mean flap ischemia time was $57.6 \pm 3.6$ (range, 32-120) min. History of smoking was repentantly recorded in only $50 \%$ of the patients. Of these patients, $40.7 \%$ were non-smokers, $24.1 \%$ were active smokers at the time of surgery and $35.2 \%$ stopped smoking prior to surgery.

In Table 1, the definitions for various complications are specified. In 59 patients $(57 \%)$, the procedure was performed uneventful. Seventeen patients (16\%) had minor flap complications (mi-FC), which were managed conservatively, and patients recovered with either no or just minor

Table 1 Definitions and abbreviations of complications

\begin{tabular}{|c|c|c|c|}
\hline Abbreviation & Definition & Severity & Cosmetics \\
\hline mi-FC & $\begin{array}{l}\text { Minor flap complications: } \\
\text { fat necrosis (without skin loss) } \\
\text { or small flap necrosis }<5 \% \text { ) }\end{array}$ & Minor & None to minor effect on cosmetic result \\
\hline ma-FC & $\begin{array}{l}\text { Major flap complication: partial } \\
\text { flap necrosis }(>5 \%)\end{array}$ & $\begin{array}{l}\text { Major; requiring reoperation: } \\
\text { debridement in theatre }\end{array}$ & Major effect on cosmetic result \\
\hline TFL & Total flap loss & Severe & $\begin{array}{l}\text { Flap failure to reconstruct, usually } \\
\text { worse cosmetic appearance }\end{array}$ \\
\hline RA & Revision of anastomosis & $\begin{array}{l}\text { Major; requiring reoperation: } \\
\text { redo of the anastomosis } \\
\text { or repositioning }\end{array}$ & $\begin{array}{l}\text { No effect on cosmetic result if procedure } \\
\text { is successful and no other complication occur }\end{array}$ \\
\hline
\end{tabular}


Table 2 Complications

Return to operating theatre

$\begin{array}{lll}\begin{array}{l}\text { Postoperative } \\ \text { bleeding }\end{array} & \begin{array}{l}\text { Anastomosis } \\ \text { revision }\end{array} & \text { Debridement } \\ \end{array}$

\begin{tabular}{lllll}
\hline mi-FC & None & None & None & 15 \\
ma-FC & 1 & 4 & $13+4^{\mathrm{a}}$ & None \\
TFL & None & 5 & $1+5^{\mathrm{b}}$ & None \\
Total & 2 & 11 & $23^{\mathrm{c}}$ & 15
\end{tabular}

${ }^{\text {a }}$ Four secondary debridement after revision of anastomosis

${ }^{\mathrm{b}}$ Five secondary debridement after revision of anastomosis

${ }^{\mathrm{c}}$ Two patients received musculocutaneous latissimus dorsi flap in conjunction with implants for reconstruction, three patients needed split skin graft for closure and in the remaining 18 patients, the defect could be closed after removable of non-viable tissue

negative effects on the aesthetic results. Twenty-nine patients had complications requiring return to the operating room. Two cases returned because of postoperative bleeding; these two patients recovered with no further complications. In one patient, failure of the anastomosis was discovered too late, and this patient had total flap loss (TFL). In 11 patients (11\%), the anastomosis was revised, and the salvage percentage after revision of the anastomosis was $55 \%$. Of the 11 anastomosis revisions, two patients had arterial occlusion, which was detected early in the postoperative period by means of absent Doppler signal. In the remaining nine patients, venous stasis was the reason for reoperation. This was usually detected at a later stage due to a positive Doppler signal form the intact arterial anastomosis. Anastomosis failure was recognised when delayed macroscopic changes resulting from venous stasis occurred. These flaps had a prolonged ischemia time and subsequent reperfusion injury. As consequence, these patients had a high rate of TFL and major flap complication (ma-FC). Five out of nine venous anastomosis revisions resulted in
TFL. In addition, all four patients with successful venous anastomosis revision developed ma-FC, requiring a second return to operating theatre for debridement.

In addition, 13 patients experienced ma-FC, which eventually resulted in a poor cosmetic appearance. This resulted in a total of 17 patients with ma-FC (15\%; Table 2).

There was an overall good cosmetic result in $79 \%$ of patients and an inferior cosmetic result in $15 \%$ of patients. Six percent of patients experienced TFL. In two of these patients, a musculocutaneous latissimus dorsi flap in conjunction of a breast implant was used for reconstruction at a later stage. Three other patients needed a split skin graft for definitive closure of the defect.

Risk factors such as obesity (defined as BMI $>28$ ), radiotherapy and chemotherapy were not associated with complications. Smoking was not found to be a significant risk factor for the development of PFL in this study [5]. However, smoking history was not meticulously recorded in this study population.

No significant differences were found in the hemodynamics (blood pressure and heart rate) and in temperature during the first $24 \mathrm{~h}$ after surgery when comparing patients with or without complications (Fig. 1). The mean volume of fluid therapy preoperatively was $4.20 \pm 0.14$ L. Haematocrit level prior to surgery was $0.39 \pm 0.03 \%$ and dropped to $0.32 \pm 0.04 \%$ at the end of the procedure. Haematocrit level had no effect on clinical outcome. Mean arterial pressure (MAP) during anastomosis was $72.1 \pm 1.4 \mathrm{mmHg}$. Normal preoperatively MAP values in patient population was $78.2 \pm 1.6$. The volume of fluid therapy (colloid + crystalloid) did not affect hemodynamics during the perioperative period (Fig. 2, analysis performed with a cut-off point of $4.2 \mathrm{~L}$ ). The use of colloid fluid therapy did not affect the total volume of fluid therapy nor did it have any effect on the outcome.

In addition, fluid therapy did not affect overall complications (Fig. 3). However, in patients who returned to
Fig. 1 Mean arterial pressure (MAP) is compared in patients with or without complications

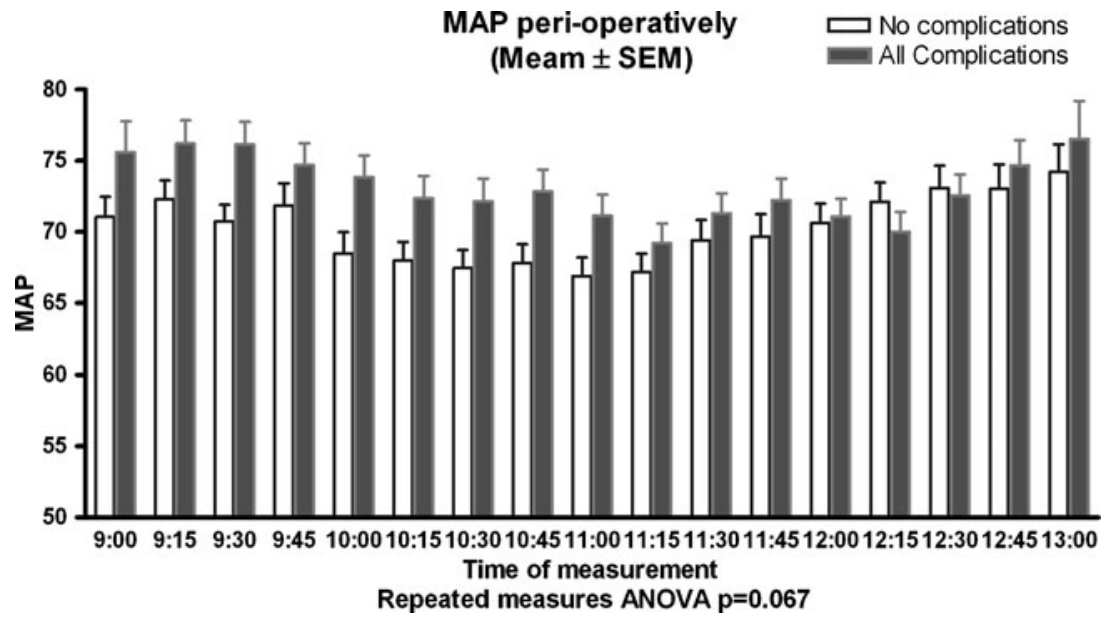


Fig. 2 The effect of fluid therapy on mean arterial pressure is shown. As a cut-off point, $4.2 \mathrm{~L}$ was used which was the mean volume of fluid therapy that was administered
Effect of volume of fluid therapy on MAP

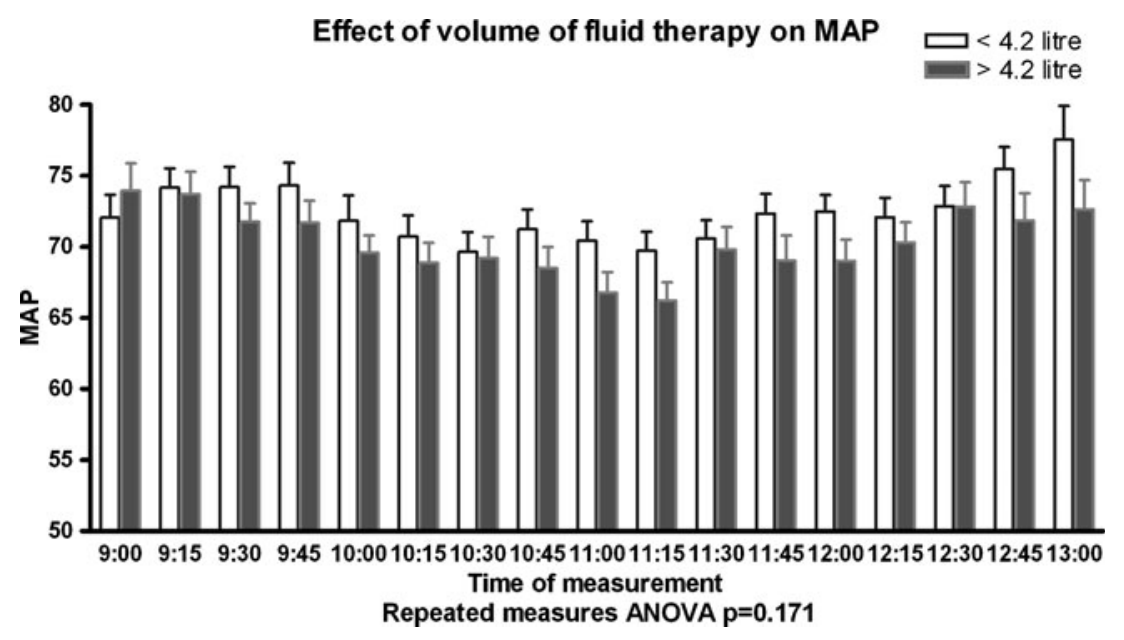

surgery due to thrombus formation of the anastomosis, the volume of fluid therapy was significantly higher (Fig. 4).

Maintenance of adequate perfusion pressure was predominantly maintained by administration of fluid therapy. However, in 14 patients, a bolus of ephedrine was used during surgery in order to maintain adequate blood pressure, which had not responded adequately on fluid therapy alone. MAP, which caused the attending anaesthesiologist to administer ephedrine, and subsequent increase in MAP are shown in Table 3. Additional details of these patients are shown in Table 3. The use of ephedrine was associated with a lower total volume of fluid therapy (Fig. 5); this was however not significant. The use of ephedrine was not related to any complications.

\section{Discussion}

Breast reconstructive surgery and flap failure pose a great burden on the self-image and the quality of life of patients

\section{Peri-operative Fluid Therapy Mean \pm SEM}

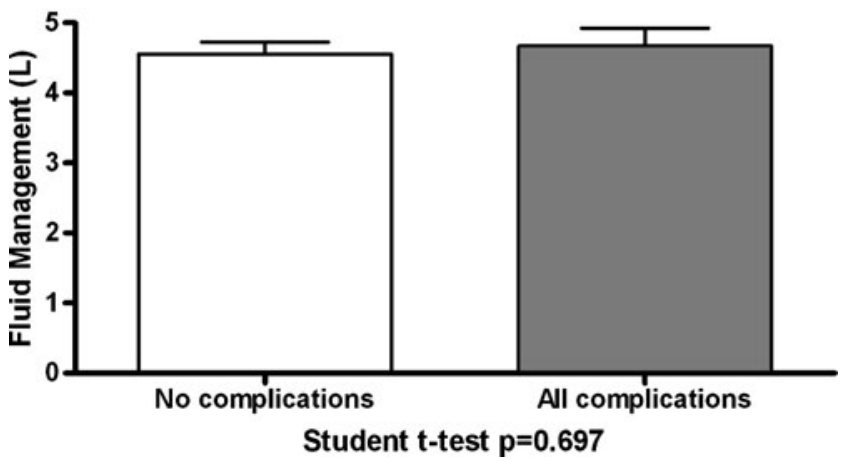

Fig. 3 Perioperative fluid therapy in patients with uneventful procedure is compared with patients who experienced one or more complications (e.g. postoperative bleeding, major flap complication, minor flap complication, total flap loss and anastomosis revision) recovering from breast cancer [6]. Increased anatomical and physiological flap knowledge has improved the outcome after autologous breast reconstructive surgery. However, there are still some uncertainties on perioperative management and the effect it may have on the final outcome. The results in this retrospective study suggest that aggressive fluid management may trigger anastomosis failure, which, in a majority of patients, leads to further complications such as TFL and increased incidence of ma-FC.

Anaesthetic management in free flap surgery has been described in the literature $[1,2,7,8]$. A series of principles such as maintenance of a high cardiac output, systolic pressure $>100 \mathrm{mmHg}$, low systemic vascular resistance, normothermia, high urine output and effective analgesia, together with a mild haemodilution to a haematocrit value of 30 $35 \%$, results in compromise. These are usually obtained by the use of a deliberate fluid management [1, 7-10]. These studies also advocate not using vasoactive agents due to either the increase in systemic vascular resistance or decrease in cardiac output. However, these basic principles

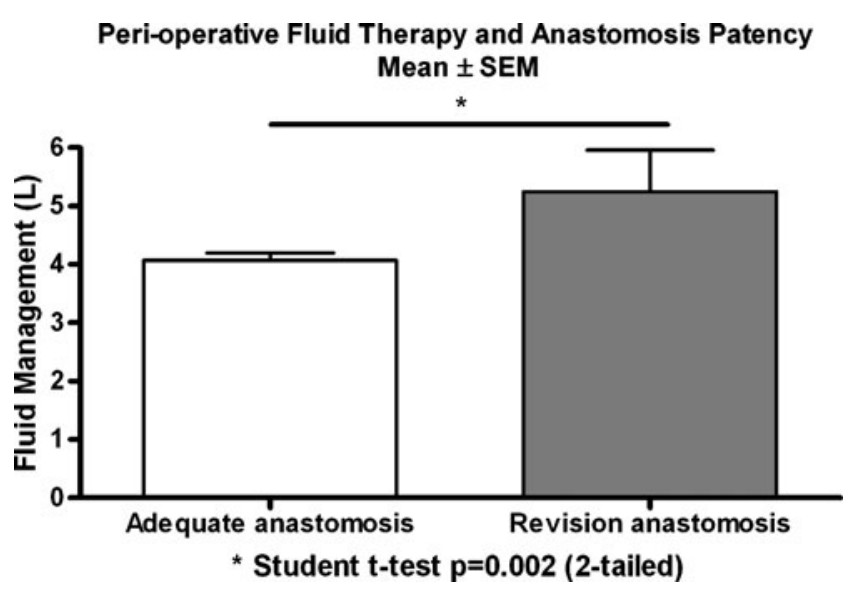

Fig. 4 Perioperative fluid therapy in patients with adequate anastomosis is compared to patients with anastomosis failure requiring anastomosis revision 
Table 3 Patient characteristics with ephedrine administration

\begin{tabular}{|c|c|c|c|c|c|c|c|c|c|c|c|}
\hline \multirow[t]{2}{*}{ Case No. } & \multirow[t]{2}{*}{ Complication } & \multirow{2}{*}{$\begin{array}{l}\text { Ephedrine, } \\
\mathrm{mg} / \mathrm{IV}\end{array}$} & \multicolumn{2}{|c|}{$\mathrm{BP}$ at TA } & \multirow[t]{2}{*}{ TA } & \multicolumn{2}{|c|}{$\mathrm{BP}$ increase } & \multirow{2}{*}{$\begin{array}{l}\text { Increase } \\
\text { MAP }\end{array}$} & \multicolumn{2}{|l|}{ BP AA } & \multirow[t]{2}{*}{ Fluid (L) } \\
\hline & & & $\mathrm{BP}$ & MAP & & $\mathrm{BP}$ & MAP & & $\mathrm{BP}$ & MAP & \\
\hline 1 & None & 10 & $90 / 45$ & 60 & B & $115 / 60$ & 78 & 18 & $115 / 65$ & 82 & 4.44 \\
\hline 2 & None & 30 & $70 / 55$ & 60 & $\mathrm{~B}$ & $105 / 65$ & 78 & 18 & $110 / 60$ & 77 & 4.10 \\
\hline 3 & None & 20 & $75 / 40$ & 52 & $\mathrm{D}$ & $100 / 60$ & 73 & 21 & $100 / 60$ & 77 & 4.60 \\
\hline 4 & $\mathrm{ma}-\mathrm{FC}$ & 10 & $80 / 45$ & 57 & $\mathrm{~B}$ & $105 / 65$ & 78 & 21 & $95 / 60$ & 72 & 6.79 \\
\hline 5 & TFL & 7.5 & $80 / 45$ & 57 & $\mathrm{~B}$ & $100 / 50$ & 60 & 3 & $70 / 50$ & 57 & 4.13 \\
\hline 6 & None & 5 & $80 / 40$ & 53 & B & $120 / 75$ & 90 & 37 & $95 / 50$ & 68 & 7.46 \\
\hline 7 & None & 5 & $95 / 35$ & 55 & B & $120 / 75$ & 58 & 3 & $110 / 60$ & 77 & 5.65 \\
\hline 8 & mi-FC & 5 & $95 / 50$ & 65 & B & $120 / 60$ & 80 & 15 & $95 / 45$ & 62 & 5.98 \\
\hline 9 & ma-FC & 40 & $65 / 40$ & 48 & $\mathrm{~B}$ & $95 / 55$ & 68 & 20 & $85 / 55$ & 65 & 4.71 \\
\hline 10 & None & 10.5 & $90 / 35$ & 53 & B & $95 / 40$ & 58 & 5 & $95 / 35$ & 55 & 5.68 \\
\hline 11 & None & 15 & $85 / 50$ & 62 & A & $105 / 65$ & 78 & 16 & $90 / 55$ & 67 & 4.75 \\
\hline 12 & mi-FC & 15 & $90 / 55$ & 67 & B & $110 / 65$ & 80 & 13 & $125 / 75$ & 92 & 5.53 \\
\hline 13 & None & 35 & $65 / 45$ & 52 & B & $95 / 45$ & 62 & 10 & $90 / 40$ & 57 & 3.30 \\
\hline 14 & None & 12.5 & $80 / 45$ & 57 & B & $100 / 60$ & 73 & 16 & $95 / 60$ & 72 & 4.91 \\
\hline
\end{tabular}

$\mathrm{BP}$ and MAP are shown in millimetres of mercury

$B P$ blood pressure, $T A$ time of administration (ephedrine), $M A P$ mean arterial pressure, $B$ before anastomosis, $D$ during anastomosis, $A$ after anastomosis

are more based on animal studies rather than on evidencebased medicine.

Anaesthesiologists view the entire body as having flow that is dependent on systemic perfusion pressure, whereas reconstructive surgeons convene that systemic administration of vasoactive agents cause vasoconstriction of the pedicle artery and the microvasculature. Clinically, vasoactive agents may lead to increased difficulty during dissecting due to vasoconstriction of perforating vessels. However, Massey et al. demonstrated the safe and effective use of epinephrine in an experimental model [11]. In addition, a clinical study comparing dopamine with dobutamine dem-

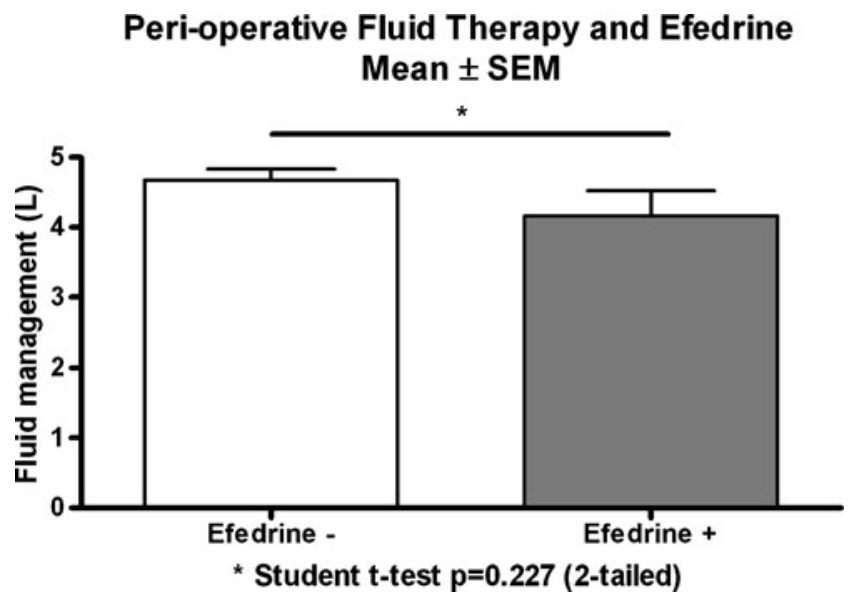

Fig. 5 Perioperative fluid therapy is compared in patients with or without ephedrine onstrated that if vasoactive agents are needed during microvascular surgery, dobutamine seems to be more beneficial than dopamine in terms of cardiac output and flap perfusion [12].

In this study, only a minor bolus of ephedrine was used in 14 patients with no adverse effects on the complication rates. Ephedrine did lead to a reduced fluid volume therapy in this group; however, this was not significant (Fig.3).

Perioperative fluid therapy is the subject of much controversy in general surgery. In respect to reconstructive free flap surgery, little is known. The flaps used in reconstructive surgery are prone to ischemia and hypoxia, which implies a considerable risk of wound healing and flap complications. Deliberate fluid therapy causes haemodilution, which may further deteriorate oxygenation because of the lack of erythrocytes. On the other hand, it could improve oxygenation because of increased microcirculatory blood flow. In experimental studies, normovolaemic haemodilution reduces risk of thrombosis [13] and increases flap oxygenation [14]. In clinical studies, the debate of deliberate fluid therapy versus restrictive fluid therapy is still ongoing $[15,16]$, although a recent review favours restrictive fluid therapy [3].

In this study, a high volume of fluid therapy during surgery was retrospectively associated with a significant higher incidence of return to the operating theatre for revision of the anastomosis. The majority of these patients developed further complications such TFL or ma-FC leading to return to the operating theatre for debridement. 
A possible pathogenic explanation is that fluid overload precipitates oedema in the flap and therefore impairs the microcirculation. This in turn leads to venous stasis and, subsequently, thrombosis. Finally, arterial perfusion is impaired in a retrograde manner. In addition, the free flaps may be especially susceptible to oedema formation due to the loss of lymphatic drainage.

Based on the results of this study, a goal-directed or more restricted intravenous fluid therapy in addition with safe use of inotropes may be recommended. Invasive monitoring such as central venous pressure and invasive arterial monitoring may guide this. Fluid loss should be replaced, but fluid overload should be avoided in breast reconstruction with free-tissue transfer.

Open Access This article is distributed under the terms of the Creative Commons Attribution Noncommercial License which permits any noncommercial use, distribution, and reproduction in any medium, provided the original author(s) and source are credited.

\section{References}

1. Macdonald DJ (1985) Anaesthesia for microvascular surgery. A physiological approach. Br J Anaesth 57(9):904-912. doi:10.1093/ bja/57.9.904

2. Sigurdsson GH (1995) Perioperative fluid management in microvascular surgery. J Reconstr Microsurg 11(1):57-65. doi:10.1055/s2007-1006512

3. Brandstrup B (2006) Fluid therapy for the surgical patient. Best Pract Res Clin Anaesthesiol 20(2):265-283. doi:10.1016/j.bpa.2005.10.007

4. Booi DI, Debats IB, Boeckx WD, van der Hulst RR (2008) A study of perfusion of the distal free-TRAM flap using laser Doppler flowmetry. J Plast Reconstr Aesthet Surg 61(3):282-288. doi:10.1016/j.bjps.2007.07.014

5. Banic A, Boeckx W, Greulich M et al (1995) Late results of breast reconstruction with free TRAM flaps: a prospective multicentric study. Plast Reconstr Surg 95(7):1195-1204, discussion 1205-6
6. Wehrens KME, Cuypers WJSS, Boeckx WD, van der Hulst RRWJ (2005) Psychological profile of women seeking breast reconstruction and quality of life assesment after surgery. Eur J Plast Surg 28:264-267. doi:10.1007/s00238-004-0709-8

7. Quinlan J (2006) Anaesthesia for reconstructive surgery. Anaesth Intens Care Med 7(1):31-35

8. Sigurdsson GH, Thomson D (1995) Anaesthesia and microvascular surgery: clinical practice and research. Eur J Anaesthesiol 12 (2):101-122

9. Banic A, Krejci V, Erni D, Wheatley AM, Sigurdsson GH (1999) Effects of sodium nitroprusside and phenylephrine on blood flow in free musculocutaneous flaps during general anesthesia. Anesthesiology 90(1):147-155. doi:10.1097/00000542-199901000-00020

10. Cordeiro PG, Santamaria E, Hu QY, Heerdt P (1997) Effects of vasoactive medications on the blood flow of island musculocutaneous flaps in swine. Ann Plast Surg 39(5):524-531

11. Massey MF, Gupta DK (2007) The effects of systemic phenylephrine and epinephrine on pedicle artery and microvascular perfusion in a pig model of myoadipocutaneous rotational flaps. Plast Reconstr Surg 120(5):1289-1299. doi:10.1097/01.prs.00 $00279371.63439 .8 \mathrm{~d}$

12. Suominen S, Svartling N, Silvasti M, Niemi T, Kuokkanen H, Asko-Seljavaara S (2004) The effect of intravenous dopamine and dobutamine on blood circulation during a microvascular TRAM flap operation. Ann Plast Surg 53(5):425-431. doi:10.1097/01. sap.0000137133.08105.73

13. Atchabahian A, Masquelet AC (1996) Experimental prevention of free flap thrombosis. II: Normovolemic hemodilution for thrombosis prevention. Microsurgery 17(12):714-716. doi:10.1002/ (SICI)1098-2752(1996)17:12<714::AID-MICR10>3.0.CO;2-X

14. Schramm S, Wettstein R, Wessendorf R, Jakob SM, Banic A, Erni D (2002) Acute normovolemic hemodilution improves oxygenation in ischemic flap tissue. Anesthesiology 96(6):1478-1484. doi:10.1097/00000542-200206000-00030

15. Arkilic CF, Taguchi A, Sharma N et al (2003) Supplemental perioperative fluid administration increases tissue oxygen pressure. Surgery 133(1):49-55. doi:10.1067/msy.2003.80

16. Brandstrup B, Tonnesen H, Beier-Holgersen R et al (2003) Effects of intravenous fluid restriction on postoperative complications: comparison of two perioperative fluid regimens: a randomized assessor-blinded multicenter trial. Ann Surg 238(5):641-648, Six flaps could be salvaged by removing the thrombus and revising the anastomosis (salvage percentage of $55 \%$ ) 